\title{
Healthy Living: Changing Your Lifestyle to Improve Your Blood Pressure ${ }^{1}$
}

\author{
Karla P. Shelnutt and Linda B. Bobroff ${ }^{2}$
}

Most people know that high blood pressure can often be improved by making smart dietary choices and choosing foods lower in sodium. But did you know there are other ways to help control high blood pressure and even prevent it? Read on to learn how making four lifestyle changes can help you keep blood pressure down.

\section{Lose Weight If You Are Overweight}

If you are overweight, you have a higher risk for certain chronic diseases and conditions such as high blood pressure (World Health Organization, 2016). Fortunately, losing weight helps decrease blood pressure. To lose weight, you have to eat fewer calories than you burn. Healthy ways to cut back calories and stay satisfied include the following:

- Eat smaller portions.

- Eat more fruits and vegetables.

- Eat foods high in fiber, such as whole grains.

- Eat slowly and stop eating when you're full.
- Eat smaller meals more often.

- Include lean protein at each meal.

- Start meals with low-calorie, filling foods such as soups and salads.

- Drink low-calorie beverages. Choose water, diet soda, tea and lemonade without sugar, or water with a splash of juice.

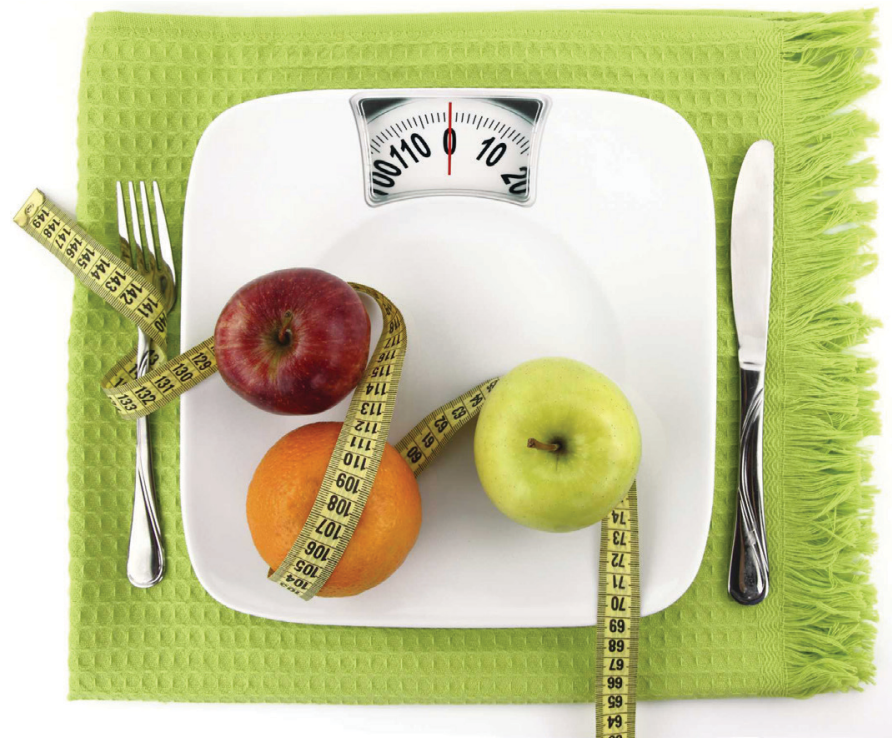

Figure 1. What and how much you eat affects your body weight and your blood pressure. Follow the tips provided for a healthy eating plan that will contribute to a healthier you. Credits: iStock

1. This document is FCS8885, one of a series of the Department of Family, Youth and Community Sciences, UF/IFAS Extension. Original publication date October 2009. Revised February 2018. Visit the EDIS website at http://edis.ifas.ufl.edu.

2. Karla P. Shelnutt, PhD, RD, associate professor; and Linda B. Bobroff, PhD, RDN, professor, Department of Family, Youth and Community Sciences; UF/IFAS Extension, Gainesville, FL 32611. 
One way to find out if you are overweight is to calculate your body mass index (BMI). This measures body fat according to your height and weight. BMI is appropriate for most healthy American men and women (National Heart, Lung, and Blood Institute, 2013). You can visit http://www.nhlbi.nih.gov/guidelines/ obesity/BMI/bmicalc.htm to calculate your BMI. If you do not have Internet access, ask your local Family and Consumer Sciences agent to calculate your BMI for you. The following table lists the BMI categories and can be used to determine if you are overweight. Table 1. Body Mass Index Categories.

\begin{tabular}{|c|l|}
\hline BMI & \\
\hline$<18.5$ & Underweight \\
\hline $18.5-24.9$ & Normal weight \\
\hline $25-29.9$ & Overweight \\
\hline$\geq 30$ & Obesity \\
\hline
\end{tabular}

National Heart, Lung, and Blood Institute (2013)

\section{Increase Physical Activity}

In addition to making smart food choices, it's important to become more active. Being active can help you lose weight, but physical activity can lower blood pressure even if weight loss does not occur. The 2008 Physical Activity Guidelines for Americans suggest that adults participate in at least 150 minutes (two and a half hours) of moderate physical activity or 75 minutes (one hour and 15 minutes) of vigorous activity each week. For moderate physical activity, this is about 22 minutes a day (U.S. Department of Health and Human Services, 2008). You don't have to do all this activity at once! Dividing it into three 10- to 15-minute intervals is just as effective. If 22 minutes a day is too much to start, try a 10- to 15-minute walk after breakfast, lunch, or dinner. Start slowly and increase your speed and distance as you are able. Moderate physical activity includes the following:

- Mowing the lawn

- Dancing

- Golf (no cart!)

- Bicycling

- Brisk walking

- Weight lifting

- Swimming

Be sure to speak with your doctor before increasing your physical activity if you have high blood pressure!

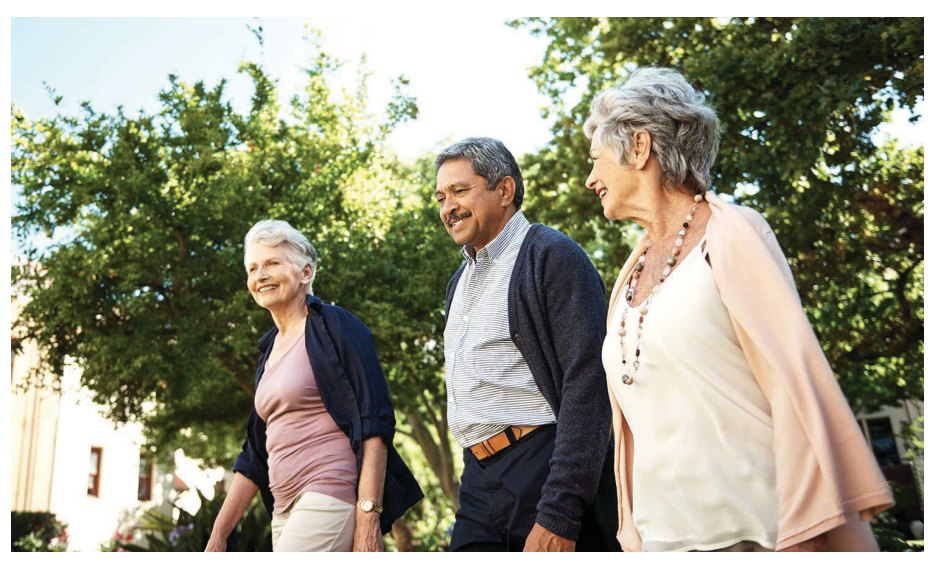

Figure 2. Physical activity is important for good health at every age. Older adults can improve their health and help to control their blood pressure by being active most days of the week. Credits: shapecharge/gettyimages

\section{Limit Alcohol Consumption}

The third lifestyle change that can help control your blood pressure is limiting the amount of alcohol you drink. Men should limit their alcohol intake to two drinks or less per day, and women (and lighter-weight men) should have one drink or less per day. Adults over 65 who are healthy and do not take medications should drink no more than seven drinks in a week. If you take medication or have a health condition, check with your health care provider to see if it is okay for you to drink alcohol (NIAAA, 2017). One alcoholic drink is defined as 12 ounces of regular beer, 4 ounces 
of wine, or $1 \frac{1}{2}$ ounces of 80 -proof distilled spirits (American Heart Association, 2015a).

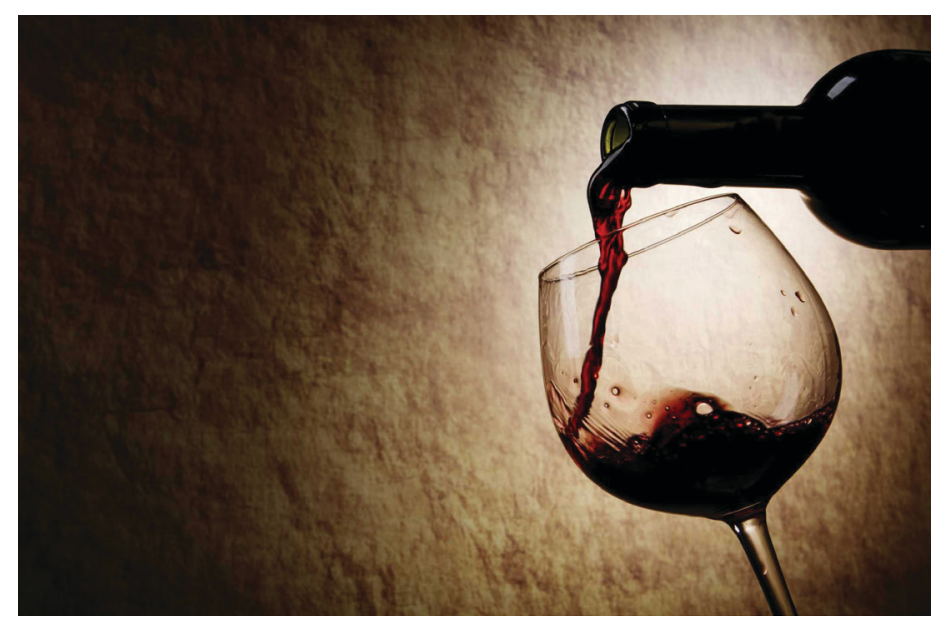

Figure 3. In addition to the daily alcohol limit recommended for all adults, older adults should limit alcohol intake to less than seven drinks per week, if they drink at all. Alcohol can interfere with some medications, so check with your health care provider to see if it is okay for you to drink alcoholic beverages. Credits: iStock

\section{Stop Smoking}

Smoking is a strong risk factor for high blood pressure, according to the American Heart Association (2015). If you smoke, quitting decreases your risk for high blood pressure, heart disease, and lung and other cancers. Talk to your doctor about quitting. Most communities offer support programs for those who want to quit. There may be some medications that help as well (American Heart Association, 2015b). Saving money is another benefit to kicking this unhealthy habit. Did you know that if you quit smoking one pack of cigarettes a day, you would save about $\$ 185$ in one month and more than $\$ 2,200$ in a year, based on the national average of $\$ 6.16$ per pack in 2017? Depending on where you live, the cost of cigarettes may vary. Nevertheless, quitting or cutting down on cigarette smoking would give you extra money to enjoy more active hobbies such as dancing or gardening.

\section{Where can I get more Information?}

Your local UF/IFAS Extension Family and Consumer Sciences (FCS) agent may have more information and/or classes for you to attend. Find your local UF/IFAS Extension office at http://solutionsforyourlife.ufl.edu/map. Also, a registered dietitian ( $\mathrm{RD}$ or $\mathrm{RDN})$ can provide reliable information. You can ask your doctor to refer you to an $\mathrm{RD}$ or $\mathrm{RDN}$ if you need diet counseling for a health condition.

For more information about high blood pressure, see EDIS document FCS8599, Healthy Living: High Blood Pressure, at http://edis.ifas. ufl.edu/fy684.

For information on how to make better dietary choices using the food label, see EDIS document FCS8883, Healthy Eating: Understanding the Nutrition Facts Label, at http://edis.ifas.ufl. edu/fy1127.

Reliable nutrition information is available on the following websites:

- http://choosemyplate.gov

- http://www.nutrition.gov

- http://www.americanheart.org

\section{References}

American Heart Association. (2015a). Alcohol and heart health. Accessed on January 19, 2018. http://www.heart.org/HEARTORG/ HealthyLiving/HealthyEating/Nutrition/Alcohol-and-Heart-Health_UCM_305173_Article. jsp\#.WVz3y6brtv4

American Heart Association. (2015b). Why quit smoking? Accessed on January 19, 2018. http://www.heart.org/HEARTORG/GettingHealthy/QuitSmoking/QuittingSmoking/ Why-Quit-Smoking_UCM_307847_Article. jsp 
National Heart, Lung, and Blood Institute. (2017). Calculate your body mass index. Accessed on January 19, 2018. http://www.nhlbi. nih.gov/guidelines/obesity/BMI/bmicalc.htm

National Institute on Alcohol Abuse and Alcoholism (NIAAA). (2017).

Older adults. National Institutes of Health. Accessed on January 19, 2018. https:// www.niaaa.nih.gov/alcohol-health/ special-populations-co-occurring-disorders/ older-adults

U.S. Department of Health and Human Services. (2008). 2008 Physical Activity Guidelines for Americans. Accessed on January 19, 2018. http://www.health.gov/paguidelines/guidelines/summary.aspx

World Health Organization. (2017). Obesity and overweight. Media centre. Accessed on January 19, 2018. http://www.who.int/ mediacentre/factsheets/fs311/en/ 